Thorax (1975), 30, 569.

\title{
Performance of heat exchangers used in whole body perfusion circuits
}

\author{
D. W . B E T H U N , R. D . G I L L, \\ a nd D. R. W HE E L D N \\ Regional Cardiothoracic Unit, Papworth Hospital, Cambridgeshire
}

\begin{abstract}
Bethune, D. W., Gill, R. D., and Wheeldon, D. R. (1975). Thorax, 30, 569-573. Performance of heat exchangers used in whole body perfusion circuits. The performance of some commonly used heat exchangers has been investigated with particular reference to the effect of varying the water flow. The results demonstrate that there is considerable variation in the performance of most units when the water flow is changed. It is suggested that more information should be provided by the manufacturers of heat exchangers and that there should be a supply of water in cardiothoracic theatres at a sufficient pressure to allow the full performance of the heat exchangers to be realized.
\end{abstract}

Systems used for total body perfusion must incorporate some mechanism for controlling the temperature of the blood in the circuit (Galletti and Brecher, 1962). Even during normothermic perfusion heat is lost to the environment and must be replaced. If hypothermia is practised there must be a reasonable heat transfer capacity available to allow control of the temperature and to avoid delays in rewarming. Some surgeons have become critical of moderate hypothermia $\left(30^{\circ} \mathrm{C}\right)$ because of delays associated with rewarming; and in some units unphysiological temperatures of around $35^{\circ} \mathrm{C}$ are accepted at the end of bypass. This may be due to the use of heat exchangers with insufficient heat transfer capacity, leading to unreasonable prolongation of perfusion time to raise the temperature to $37^{\circ} \mathrm{C}$. Given the desirability of having a heat exchanger in any whole body perfusion circuit, it is important to use one with a performance sufficient to allow rapid and efficient temperature control.

Information on the performance of heat exchangers is limited, and the effect of changes in the water flow on the performance has been largely ignored. In some studies no mention is made of the water flow through a heat exchanger when quoting experimental results (Rygg, 1973), and in others (Peirce, 1962; Galletti, and Brecher, 1962) the results were obtained at a given water flow with no indication of the effect of changing the water flow. Manufacturers' information on their products is limited and at best comprises a performance curve covering different blood flows with no indication of the effect of a change in the water flow.

The purpose of this investigation was to study the influence of changes in the water flow on heat exchanging capacity.

\section{METHOD}

We constructed a circuit which allowed variation of blood and water flow through a variety of heat exchangers (Table). Four of the units tested had the heat exchanger built into a disposable oxygenator. The Harvey $\mathrm{H} 100$ and the Rygg Venotherm HL238DF have a heat exchanger element in the bubble column of the unit, and the Temptrol Q100 and the Rygg Thermo HL237DF oxygenators have the heat exchanger in the arterial reservoir. These units were compared with a disposable venous line heat exchanger (Baxter venous 5M0335) and a nondisposable annular arterial line heat exchanger (NEP 2131). The blood circuit was primed with time-expired ACD blood and Hartmann's solution and comprised a closed loop with the device under test, a roller pump, and a second heat exchanger to keep the blood in the circuit at a temperature comparable with that found in clinical practice.

The temperature of the blood in and out of the heat exchanger and of the water out of the heat exchanger was measured using Ellab ${ }^{1}$ thermocouples. This allowed the calculation of a per-

${ }^{1}$ Sirex Limited, Clipstone Street, London 
formance factor by substituting in the equation:

$$
\text { Performance Factor }=\frac{\text { Temperature blood in-Temperature blood out }}{\text { Temperature blood in-Temperature water out }}
$$

This gives a numerical value for the performance of a unit which is independent of the actual blood and water temperatures; an ideal unit would have a performance factor of $\mathbf{1 . 0}$.

We tested one sample of each type of heat exchanger; at each blood and water flow the temperatures were measured on two occasions. The Temptrol Q100 unit was the only one in which a difference was found between the two sets of measurements. We had observed variable streaming in the arterial reservoir of the Temptrol unit and this may have affected the performance factor; in the case of this unit the readings were averaged to give the final result.

The figures for the surface area and blood film thickness in the Table were obtained by direct measurement and calculation.

\section{RESULTS}

COMPARISON OF UNITS AT FIXED WATER FLOW The performance of each of the units at variable blood flows between 1 and 6 litres per minute and at a fixed water flow of 15 litres per minute is shown in Figure 1.

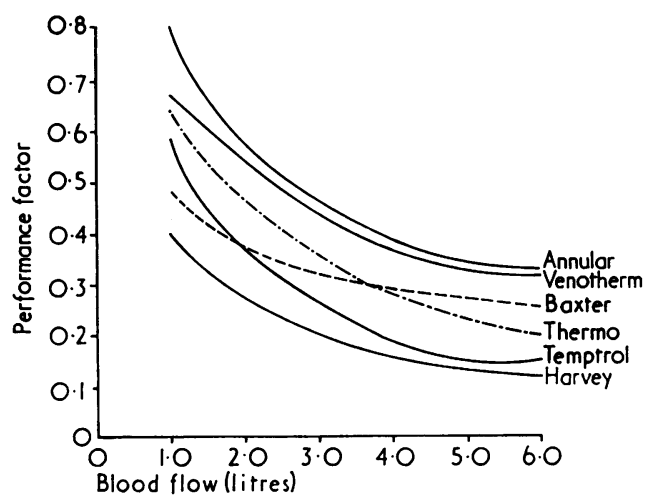

FIG. 1. Performance curves for four combinede oxygenator/heat exchangers and two separate hea ㄱ exchangers at a water flow rate of 15 litres per minute.

The annular NEP 2131 has the best performo ance at all blood flows. The Rygg Venothermo HL238DF is the only disposable unit which approaches this performance over the range of blood flows tested.

T A B L E

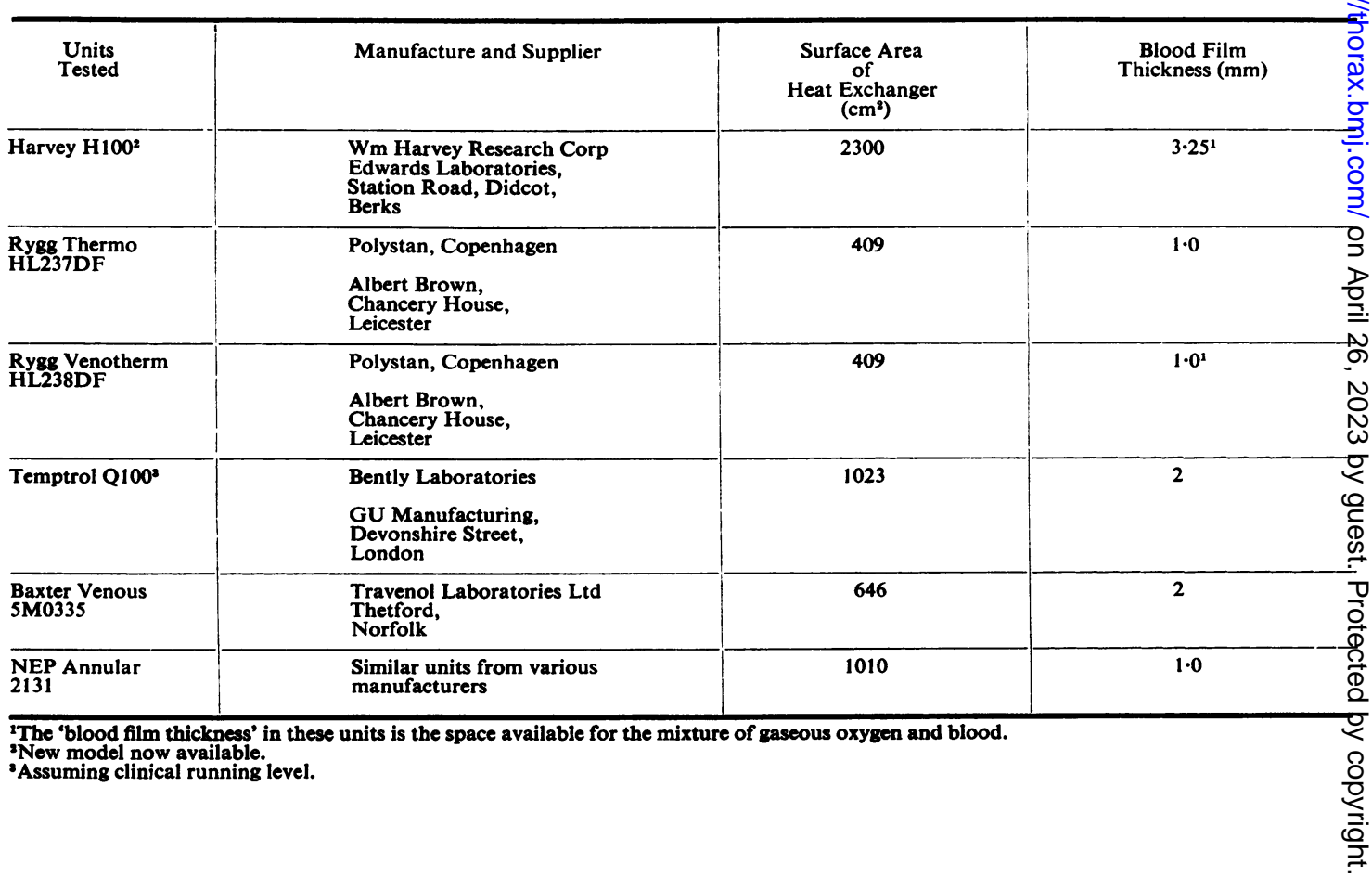


The arterial reservoir heat exchangers, Temptrol Q100 and Rygg Thermo HL237DF, showed marked improvement in performance at blood flows below 2 litres per minute. At a blood flow of 6 litres per minute the Temptrol has a performance factor which is half that of the more efficient annular and venotherm units.

The relative performance of the Baxter venous line heat exchanger fell as the blood flow was reduced, but at a blood flow of 6 litres per minute only the annular NEP and Rygg Venotherm units had a better performance.

The Harvey $\mathrm{H} 100$ had the poorest performance at all flows. Its heat exchanging capacity was less than half that of the annular and Venotherm units at all blood flows from 1 to 6 litres per minute.

EFFECT OF VARYING THE WATER FLOW Figure 2 illustrates the effect of increasing the water flow through the two oxygenator column heat exchangers. At a blood flow of 6 litres per minute the performance factor of the Rygg Venotherm increases from 0.18 to 0.34 (89\% increase) when the water flow is changed from 5 to 20 litres per minute. With the same change in water flow the performance factor of the Harvey $\mathrm{H} 100$ increases only from 0.12 to 0.145 ( $21 \%$ increase).

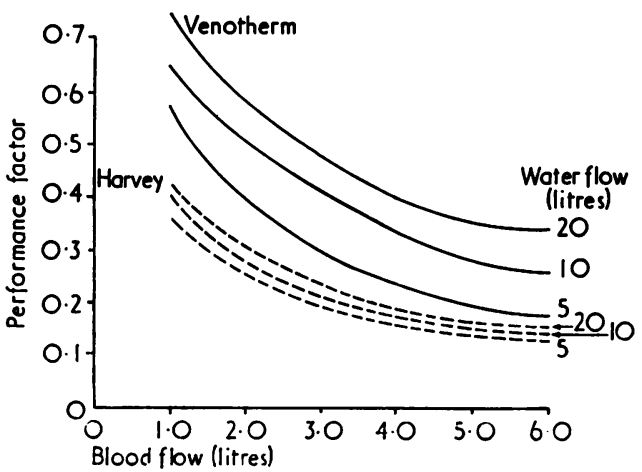

FIG. 2. Performance curves for two combined oxygenator/heat exchangers, both of which have the heat exchange element built into the bubble column.

EFFECTIVE BLOOD FILM THICKNESS The performance curves illustrated in Figure 3, where two units with identical heat exchanger elements are compared, suggest that the effective blood film is greatly reduced when the heat exchanger element is moved from the arterial reservoir to the oxygenating column. This makes it difficult to obtain meaningful values for blood film thickness

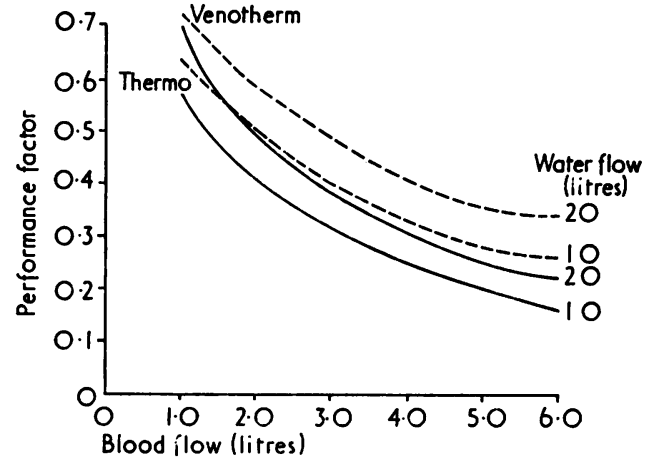

FIG. 3. Comparable curves for two disposable units which use the same heat exchange elements. In the Venotherm the heat exchange element is in the bubble column; in the Thermo it is in the arterial reservoir.

when the heat exchanger element is situated in the oxygenator column.

WATER PRESSURE The pressure gradients across the water paths plotted against water flows are shown in Figure 4. The unit with the highest resistance to water flow is the Baxter unit, and this requires a pressure differential of $10 \mathrm{lb} / \mathrm{in}^{2}$ to give a water flow of 15 litres per minute; considerable distortion of this unit occurred at higher water flows and pressures. It is interesting that at a water flow of 20 litres per minute the pressure differential across the Temptrol unit is only $7 \mathrm{lb} / \mathrm{in}^{2}$. This means that the restriction for the maximum pressure on the Temptrol unit of $10 \mathrm{lb} / \mathrm{in}^{2}$ will allow a high flow of water to be used. The pressure differential on the Rygg units is only $6 \mathrm{lb} / \mathrm{in}^{2}$, at a water flow of 20 litres per minute. This allows a very considerable safety margin as the heat exchanger elements of the

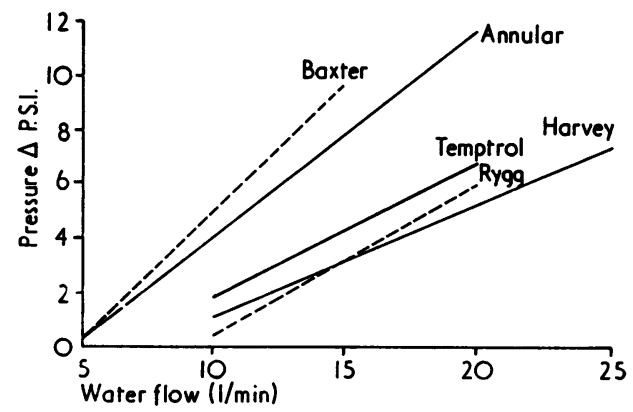

FIG. 4. Water pressure differential across the heat exchange elements at various water flows. 
Rygg units are tested to $40 \mathrm{lb} / \mathrm{in}^{2}$ during manufacture.

\section{DISCUSSION}

From the results it appears that many factors affect the performance of heat exchangers. These include the effective surface area, blood film thickness, water flow, and blood flow. However, our results indicate that manufacturers should be encouraged to give detailed results of tests carried out on their units, and that these should include performance factors for a range of blood and water flows.

The only explanation we can find for the poor heat exchange performance of the Harvey H100 unit is that the polycarbonate tubes which separate the blood and water pathways provide an undesirable degree of insulation.

Previous investigators have measured the performance of heat exchangers at a single water flow, probably in the belief that changes in the water flow would not affect the relative performance of the units. The comparison of the two venous column heat exchangers (Fig. 2) demonstrates that this assumption is unwarranted. One unit had a $89 \%$ increase in performance when the water flow was increased from 5 to 20 litres per minute, whereas the same change in water flow produced only a $21 \%$ increase in performance in the other unit.

The units studied are all adult units produced for use with blood flows up to 6 litres per minute.

The annular unit (NEP2131) has a blood priming volume of $65 \mathrm{ml}$ and is suitable for use in circuits where a low blood priming volume is desirable. The Rygg Venotherm HL238DF and Thermo HL237DF oxygenators are available in a range of sizes all using the same heat exchange element. In addition to the Temptrol Q100 we tested a Temptrol Q110 paediatric unit which had a similar performance curve to that found in the adult unit at blood flows below 3 litres per minutes with a water flow of 15 litres per minute. This means that in the examples where similar or identical heat exchanger elements are used for adult and paediatric circuits, the paediatric circuits will be relatively more efficient with regard to the heat exchanging ability as the blood flows will be lower.

\section{CONCLUSIONS}

Our results indicate that there is no need for water flows in excess of 20 litres per minute through currently available heat exchangers an民 that a water pressure of $20 \mathrm{lb} / \mathrm{in}^{2}$ is sufficient $\mathrm{t}^{\circ}$ give this rate of flow through the units we testeథ and also to overcome the resistance of the pipingo mixing valves, and outlet tubing which may be used in the water circuit connecting to the heat exchange element.

We recommend that cardiothoracic theatre $\overrightarrow{s u}$ should have water supplies for the extracorporea? heat exchangers, either from the hospital main $\vec{x}$ or from separate heater/cooler units capable of providing a water flow of 20 litres per minute aer a maximum pressure head of $20 \mathrm{lb} / \mathrm{in}^{2}$. Thg delivery pressure should be adjustable to accommodate units such as the Temptrol oxygenator\% which have a maximum safe working pressure of $10 \mathrm{lb} / \mathrm{in}^{2}$.

The results we have obtained demonstrate tha悉 a disposable oxygenator column heat exchanges can give a performance approaching that of atb annular arterial line unit. There is an additiona advantage in having the heat exchanger situated in the oxygenator column as any gas bubbleo liberated as a result of rapidly induced temperas ture changes in the blood occur before the defoamer and arterial reservoir.

The use of water flows from the hospital mains of 20 litres per minute should be restricted toㅡㅁ occasions when it is desirable to change the patient's temperature rapidly. For this reason we recommend reducing the flow through the heat exchanger element when the desired patient temperature has been achieved.

We are grateful to Mr. T. A. H. English and ME B. B. Milstein for helpful advice and encouragement to the Department of Medical Photography, Adder? brooke's Hospital, for the illustrations, and to Miss G. Holland for secretarial assistance.

\section{REFERENCES}

Galletti, P. M. and Brecher, G. A. (1962). In Hea民ึ Lung Bypass, Chapter XI, p. 165. Grune and Stratton, New York and London.

Peirce, E. C. II. (1962). A simplified heat exchange્ for perfusion hypothermia. Archives of Surgery, 84, 329.

Rygg, I. H. (1973). In Studies in Extracorpore ब্ु Circulation, Chapter 6, p. 99. Fadls Forlag, Københaven, Århus, Odense.

ADDENDUM

In the short period since this study was completê one new unit (Galen Optiflow) has become avaif able in Britain, the only information on the 
performance of its heat exchanger is the statement that it 'has the most efficient heat exchanger available in a disposable system'. Actual testing indicates a performance approaching that of the Rygg Venotherm. In addition two manufacturers have introduced improved heat exchangers in their disposable oxygenator units (Harvey and Temptrol). In both cases an improvement in performance is claimed but no experimental results are available from the manufacturers. With the rapid development of new and improved units the manufacturers and distributors of disposable heart-lung equipment must be encouraged to test the function of their products, where this is possible, and to make the results available.

Requests for reprints to: Dr. D. W. Bethune, Department of Anaesthesia, Papworth Hospital, Papworth Everard, Cambridge CB3 8RE. 